\title{
Optical Time Domain Demultiplexing using Fano Resonance in InP Photonic Crystals
}

Bekele, Dagmawi Alemayehu; Yu, Yi; Bony, Pierre-Yves; Ottaviano, Luisa; Oxenløwe, Leif Katsuo; Yvind, Kresten; Mørk, Jesper

Publication date:

2017

Document Version

Publisher's PDF, also known as Version of record

Link back to DTU Orbit

Citation $(A P A)$ :

Bekele, D. A., Yu, Y., Bony, P-Y., Ottaviano, L., Oxenløwe, L. K., Yvind, K., \& Mørk, J. (2017). Optical Time Domain Demultiplexing using Fano Resonance in InP Photonic Crystals. Abstract from The 2017 European Conference on Lasers and Electro-Optics, Munich, Bavaria, Germany.

\section{General rights}

Copyright and moral rights for the publications made accessible in the public portal are retained by the authors and/or other copyright owners and it is a condition of accessing publications that users recognise and abide by the legal requirements associated with these rights.

- Users may download and print one copy of any publication from the public portal for the purpose of private study or research.

- You may not further distribute the material or use it for any profit-making activity or commercial gain

- You may freely distribute the URL identifying the publication in the public portal 


\title{
Optical Time Domain Demultiplexing using Fano Resonance in InP Photonic Crystals
}

\author{
D. A. Bekele, Y. Yu, H. Hu, P.-Y. Bony, L. Ottaviano, L. K. Oxenlowe, K. Yvind, and J. Mork \\ DTU Fotonik, Technical University of Denmark, 2800 Kongens Lyngby, Denmark
}

Ultra-compact photonic structures that perform high-speed low-energy optical signal processing are essential for enabling integrated photonic chips that can meet the growing demand for information capacity [1]. Here, we demonstrate all-optical $40 \mathrm{Gbit} / \mathrm{s}$ to $10 \mathrm{Gbit} / \mathrm{s}$ demultiplexing of an optical time domain multiplexed (OTDM) signal using an InP photonic crystal switch. The device is realized using a membrane structure, where a pointdefect nanocavity is side coupled to a photonic crystal line-defect waveguide as shown in Fig. 1(a). The discrete cavity mode interacts with continuum modes of the waveguide creating a Fano resonance [2]. By placing a partially transmitting element (PTE) in the waveguide, the coupling between the waveguide and the cavity can be controlled [3]. The Fano lineshape is characterized by a large on-off transmission ratio with small spectral separation making it suitable for switching applications (Fig. 1(b)).

A $40 \mathrm{Gbit} / \mathrm{s}$ OTDM data signal is coupled to the device together with a $10 \mathrm{GHz}$ pump pulse. When the pump pulse couples into the nanocavity, free carriers are generated by two-photon absorption, which induce a blue shift in the resonance frequency through plasma dispersion and bandfilling effects [4], allowing the OTDM signal to transmit through the waveguide. The eye diagrams of the OTDM signal, pump pulse and the demuliplexed channels are shown in Fig. 1(c). The demultiplexed channel has an extinction ratio of $3 \mathrm{~dB}$.

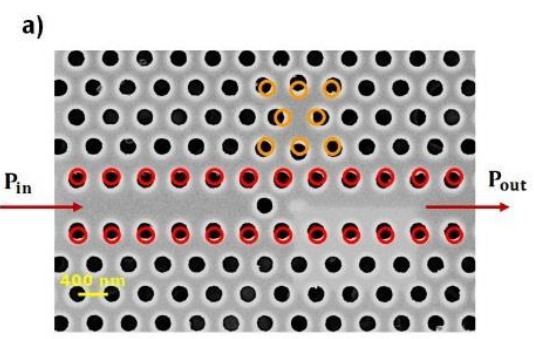

c)

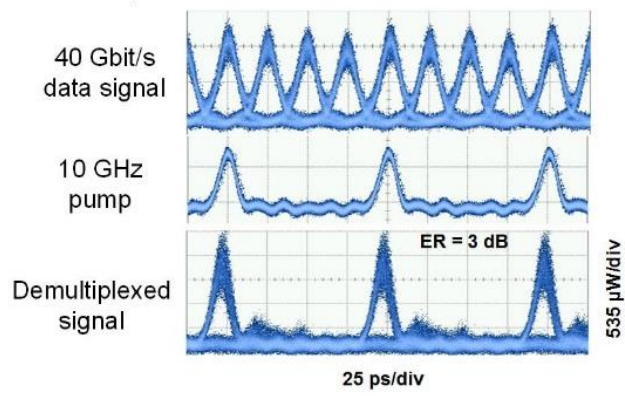

b)

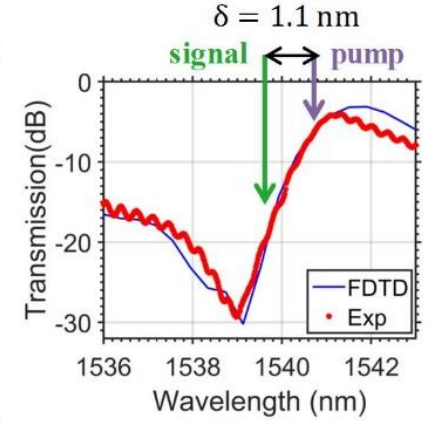

d)

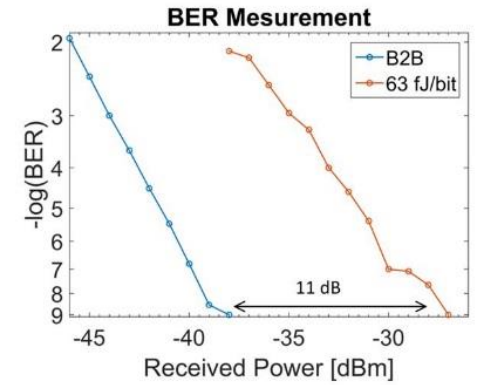

Fig. 1 (a) Scanning electron microscope (SEM) image of the device. The positions of the inner rows of holes and around the nanocavity have been optimized compared to the periodic structure (illustrated by coloured circles). (b) Experimentally measured transmission spectrum and finite difference time domain (FDTD) fitting. The pump and the signal are spectrally separated by $1.1 \mathrm{~nm}$. (c) eye diagrams of the $40 \mathrm{Gbit} / \mathrm{s}$ input OTDM data signal, the $10 \mathrm{GHz}$ pump signal and demuliplexed signal (d) BER measurement for demultiplexed signal, corresponding to a pump energy of $63 \mathrm{fJ} / \mathrm{bit}$, and back-to-back (B2B) measurements.

Bit-error-ratio (BER) measurements (Fig. 1(d)) of the $10 \mathrm{Gbit} / \mathrm{s}$ demultiplexed signal clearly show errorfree performance with power penality of $\sim 11 \mathrm{~dB}$ at a BER of $10^{-9}$ compared to a $10 \mathrm{Gbit} / \mathrm{s}$ back-to-back (B2B) with switching energy of $63 \mathrm{fJ} / \mathrm{bit}$. These results show the potential of Fano resonance based InP photonic crystal switches for fast and energy efficient all-optical data communication applications. At the conference, the prospects of realizing demultiplexing at higher data rate such as $100 \mathrm{Gbit} / \mathrm{s}$ will be discussed.

\section{References}

[1] D. A. B. Miller, " Device requirements for optical interconnects to silicon chips," Proc. IEEE 97, 1166 (2009).

[2] U. Fano, "Effects of configuration interaction on intensities and phase shifts," Phys. Rev. 124, 1866-1878 (1961).

[3] Y. Yu, H. Hu, L. K. Oxenløwe, K. Yvind, and J. Mork, "Ultrafast all-optical modulation using a photonic crystal Fano structure with broken symmetry," Opt. Lett. 40, 2357-2360 (2015).

[4] Y. Yu, E. Palushani, M. Heuck, N. Kuznetsova, P. T. Kristensen, S. Ek, D. Vukovic, C. Peucheret, L. K. Oxenløwe, S. Combrié, A. De Rossi, K. Yvind, and J. Mørk, "Switching characteristics of an InP photonic crystal nanocavity: Experiment and theory," Opt. Express 21, 31047-31061 (2013). 